\title{
THE ASSESSMENT OF SURFACE WATER QUALITY IN THE LEPENC RIVER BASIN USING WATER QUALITY INDEX (WQI) METHODOLOGY
}

\author{
P. S. Bytyçi ${ }^{1,2}$, H. S. Çadraku ${ }^{4, *}$, F. N. Zhushi Etemi ${ }^{1}$, M.A. Ismaili ${ }^{2}$, \\ O.B. Fetoshi ${ }^{3}$ and A.M. ShalaAbazi \\ ${ }^{1}$ Department of Biology/Faculty of Mathematics and Natural Sciences, University of \\ Prishtina"Hasan Prishtina", George Bush, Prishtina 10000, Kosovo \\ ${ }^{2}$ Southeast European University (SEEU), Ilindenska no 335 Tetovo, FYR Macedonia \\ ${ }^{3}$ Faculty of Tourism and Environment /University of Applied Sciences, Ferizaj, 70000, Kosovo \\ ${ }^{4}$ Faculty of Civil Engineering and Infrastructure /University for Business and Technology, \\ Kalabira 10000, Pristina, Kosovo \\ ${ }^{5}$ Faculty of Management in Tourism, Hotels and the Environment University "Haxhi Zeka", \\ Pejë, Kosovo \\ *E-mail: haziri_07@hotmail.com
}

\begin{abstract}
Surface waters in the Lepenc river basin have been under the influence of a large number of contamination factors of anthropogenic nature over the last two decades. Contaminations from the soil surface easily reach surface waters, modifying water quality. Today there are many methods that are used to classify surface water quality. This paper aims to demonstrate the state of surface water quality based on the water quality index (WQI). To investigate the WQI in the Lepenc river basin, data was measured in spring, summer, and autumn of 2017. According to WQI, the waters in the Lepenc river basin, including Nerodime and Lepenc rivers, vary from WQI-36 to WQI-76.

Keywords: Surface Water, Water Quality Index, Pond, Quality, Pollutant, Lepenc.
\end{abstract}

(C) RASĀYAN. All rights reserved

\section{INTRODUCTION}

The rapid urban development process, agriculture, and industrial development have all affected the quality of surface waters in the Lepenc river basin. The main source of surface water pollution in this basin are urban discharges containing organic compounds, soluble compounds of phosphorus and nitrogen that drive the process of eutrophication, pathogenic bacteria and viruses, and heavy metals and other substances that degradation their natural condition. The Lepenc Basin is situated in the southern part of the Republic of Kosovo. It covers an area of $53 \mathrm{~km}^{2}$ and is considered to be the richest area of surface waters. Its main rivers are Nerodime River and Lepenc River. Current assessments of the quality of water in this basin indicate that the pollution of these waters come from urban wastewater, drainage of waters polluted by diffuse pollution from agriculture, industry, and the uncontrolled use of inert ingredients along with the river's flow for various activities.

\section{Study Area}

The river Lepenci is located in the southeast of the Republic of Kosovo. It originates in the Oshlak mountains at an altitude of $2212 \mathrm{~m}$; its total length is $50 \mathrm{~km}$ and has a slope of $2.1 \%$. Annual average flow is $8.4 \mathrm{~m} 3 / \mathrm{s}$. The minimum flow of the river Lepenci $1.8 \mathrm{~m} 3 / \mathrm{s}$, as shown at the Hydrometric Station in Hani i Elezit ${ }^{1}$.

The river Lepenci represents the main catchment area in the southeastern region of Kosovo. It has an area of $652 \mathrm{~km} 2$ covering $5.98 \%$ of the territory of the Republic of Kosovo. The area where the river Lepenci 
flows is characterized by continental and mountain climate. The average annual rain autumn is $861.4 \mathrm{~mm}$, while the average annual temperature is $10.2^{\circ}$.

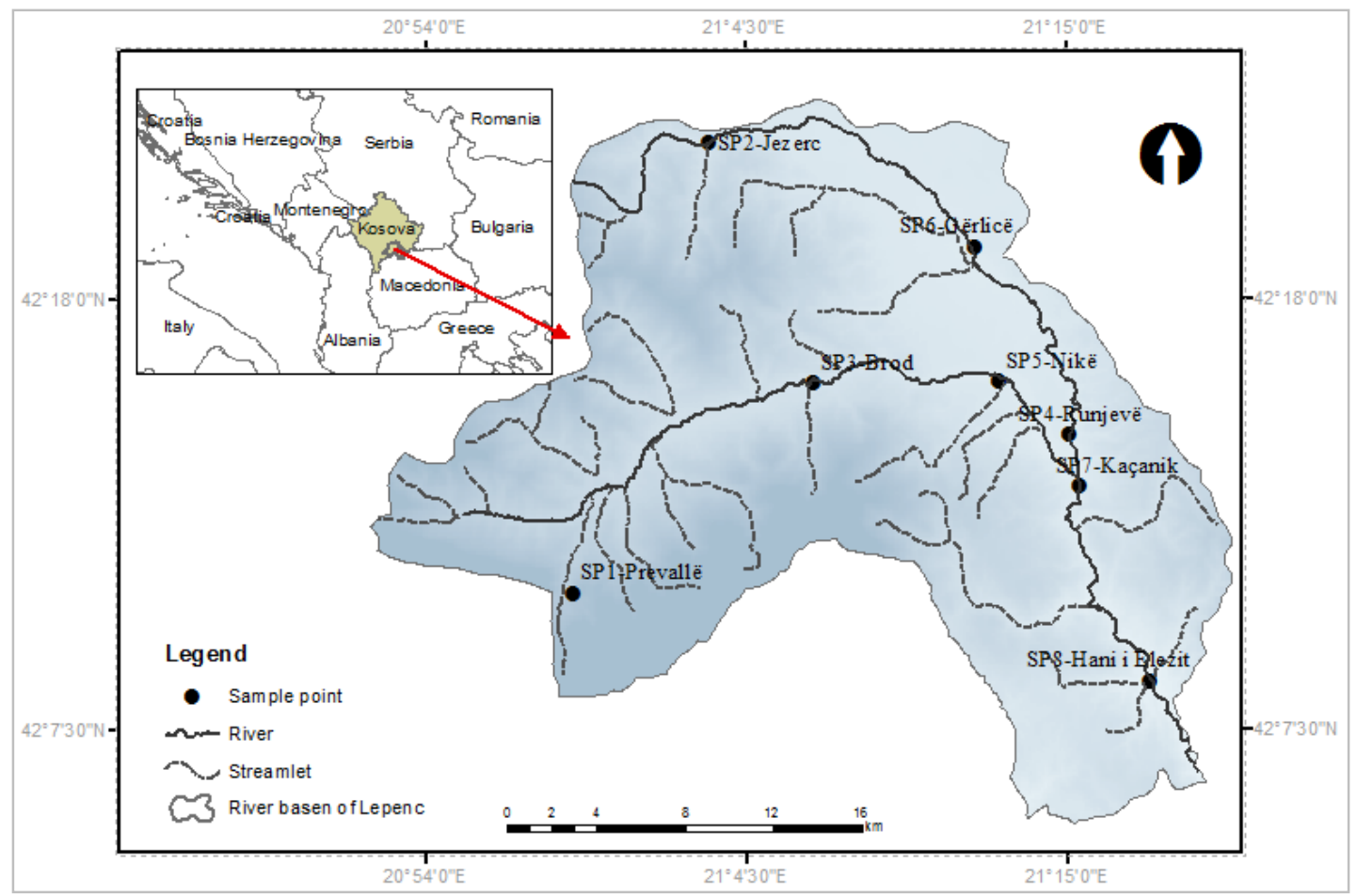

Fig.- 1: Physical-geographical position of the study area.

\section{Material and Methods}

\section{EXPERIMENTAL}

WQI is an excellent management and general administrative tool in communicating water quality information ${ }^{3}$.This index has been widely field tested and applied to data from a number of different geographical areas all over the world. In order to calculate the WQI of various water bodies, critical pollution parameters were considered. ${ }^{4}$ The WQI, which represents a tool to rate water quality for the selected parameters, was used in this paper. The methodology of rating surface water quality according to WQI was carried out in the following steps:

1. Assigning points and collecting water samples; ${ }^{3}$

2. Laboratory analysis;

3. Data processing;

Calculating WQI based on the following equation:

$$
\mathrm{WQI}=\sum \mathrm{q}_{\mathrm{i}} \mathrm{W}_{\mathrm{i}}^{3}
$$

$\mathrm{WQI}=0.17 * \mathrm{q}_{\mathrm{i}}\left(\mathrm{O}_{2}\right)+0.11 * \mathrm{q}_{\mathrm{i}}\left(\mathrm{BOD}_{5}\right)+0.16 * \mathrm{q}_{\mathrm{i}}(\mathrm{FC})+0.11 * \mathrm{q}_{\mathrm{i}}(\mathrm{pH})+0.10 * \mathrm{q}_{\mathrm{i}}(\mathrm{T})+0.07 * \mathrm{q}_{\mathrm{i}}(\mathrm{TS})+$ $0.10 * \mathrm{q}_{\mathrm{i}}\left(\mathrm{P}_{\mathrm{tot}}\right)+0.10 \mathrm{qi}\left(\mathrm{NO}_{3}\right)+0.08 * \mathrm{q}_{\mathrm{i}}(\mathrm{Tur})$

Where: $q_{i}$ is the sub-index of water quality, which indicates the quality of water in reference to 100 for each parameter; $\mathrm{w}_{\mathrm{i}}$ is the relative weight of each parameter in terms of general quality of water. ${ }^{11}$ 


\section{Interpreting Results and Drawing Conclusions}

Water quality parameters were measured using highly sophisticated measuring equipment, which was in line with international standards. Water temperature was measured using HI 98130 probe compliant to DIN 38404-C4 standard; Biochemical Oxygen Demand was measured using Winkler compliant to ISO 5815; Dissolved Oxygen and Saturation with $\mathrm{O}_{2}$ were measured using HI 9146 probe compliant to ISO 5814: 2012; Total phosphate was analyzed using SECOMAN Prim Light compliant to ISO 6878; The hydrogen ion concentration was measured using HI 98130 probe based on the standard DIN 38404-C5; Nitrates were measured using SECOMAM prim light compliant to DIN 38405-D9 standard; Turbidity was measured using AQUALITIC/PC COMPACT meter compliant with ISO 7027; Total Suspended Solids were measured using AADAMLAB250 meter compliant to EN 872 standard ${ }^{5}$.

The samples taken from the surface water of Lepenc River were used as the research material. Samples were collected from the water surface at the depth of about $10-15 \mathrm{~cm}$ near the edge or the base of the stream using sterile glass bottles.

The collected samples were then brought to the Microbiology Laboratory for biological (microbiological) analysis. The microbiological analysis of the water was conducted in order to determine the total number of Fecal Coliform bacteria.

The nutrients through which Fecal Coliform bacteria were cultured, grown, incubated and counted were (Violet red bile agar (VRBA).

It should be noted that the preparation of nutrients, their culture, incubation, equipment manipulation and the whole activity at the Microbiology Laboratory have been completely done under sterile conditions ${ }^{6}$.

Working method

First, the samples were diluted using the dilution series of $10^{1}-10^{6}$. All the dilutions were cultured in order to ascertain which of them give the required number of colonies; in the case of Petri dish it was the diameter $\varnothing$ (fi) of $10 \mathrm{~cm}$. To perform a microbiological examination, $0.45-\mu \mathrm{m}$-pore-size membrane filters were applied; the membrane filter filtered microorganisms during the liquid sample filtration, which in our case is water, and after filtration, the membrane filter was placed in Petri dishes containing nutrients ${ }^{6,7}$.The number of cells was determined by the number of colonies because it is considered that a cell represents a colony. The determination of the cells in a given sample quantity was done according to the equation ${ }^{8}$ :

$$
\text { No. of cells } / \mathrm{ml}=(\text { Number of colonies }+ \text { dilution factor }) /(\text { Volume of culture plate })
$$

In all cases after culturing, the counting was made as follows: In the plates containing Coliform Fecal bacteria all the colonies regardless of their shape, size, texture, elevation, etc., were counted.

It should be noted that the incubation time for Fecal Coliform bacteria was 24 to 48 hours at $37^{\circ} \mathrm{C}$. Finally, it should be noted which dilution was cultured 3 times in parallel with the aim of obtaining the most accurate results.

\section{RESULTS AND DISCUSSION}

The WQI method presents a way to rate surface water quality based on 9 (nine) selected parameters. Each of the selected parameters is of the same significance to the overall quality of water, that is, each of them affects WQI with its weight (wi) and the quality rating (qi) according to the impact it has on quality degradation. For the interpretation of the obtained results and rating water quality according to WQI, the Canadian method was applied, according to which five water quality classes are divided into the following: 90-100 excellent, 70-90 good, 50-70 medium, 25-50 bad, and 0-25 very bad (Table-1) ${ }^{12}$.

Table-1: Classification of River Water Based on WQI

\begin{tabular}{c|c|c|c|c|c}
\hline Range WQI & $90-100$ & $70-90$ & $50-70$ & $25-50$ & $0-25$ \\
\hline Quality & Excellent & Good & Medium & Bad & Very bad \\
\hline
\end{tabular}

\section{5}




\section{WQI at Station $\left[S_{1}\right]$}

Water Quality Index (WQI) in the upper part of Lepenci River (S1) during the three seasons: spring, summer and autumn indicated values as in Fig.-2. WQI's highest value was obtained during autumn (WQI 76), whereas the lowest value was obtained during spring (WQI 72). In general, during all seasons the water in this river showed a good quality index (Class "B"), though with a slight fluctuation of quality decline during spring. This decline, or slight tendency of quality decline, at S1 station of this river is estimated to be due to the fact that summer and spring are characterized by a higher biological activity, and especially in spring this decline in quality of water at station S1 of this river is associated with increased intensity of precipitation, which through the flow brings water into the surface areas in which there are urban waste and other pollutants.

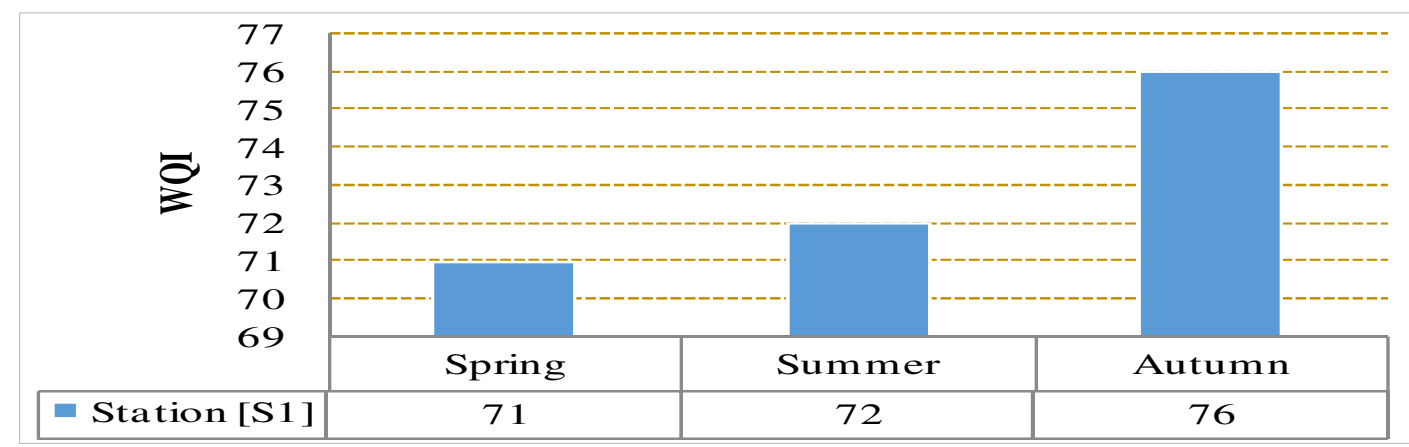

\section{WQI at Station $\left[S_{2}\right]$}

Fig.- 2: WQI in the sampling station S1

Water Quality Index (WQI) at (S2) station during the three seasons: spring, summer and autumn indicated values as in Fig.-3. At this station, WQI's highest value was obtained during the autumn season (WQI 57), whereas the lowest value was obtained during summer (WQI 50). In general, in all three seasons, the water according to WQI was of medium quality, thus belonging to class "C" in terms of quality. Class "C" means Medium, WQI: 50-70 (Drinking water source after conventional treatment and disinfection).

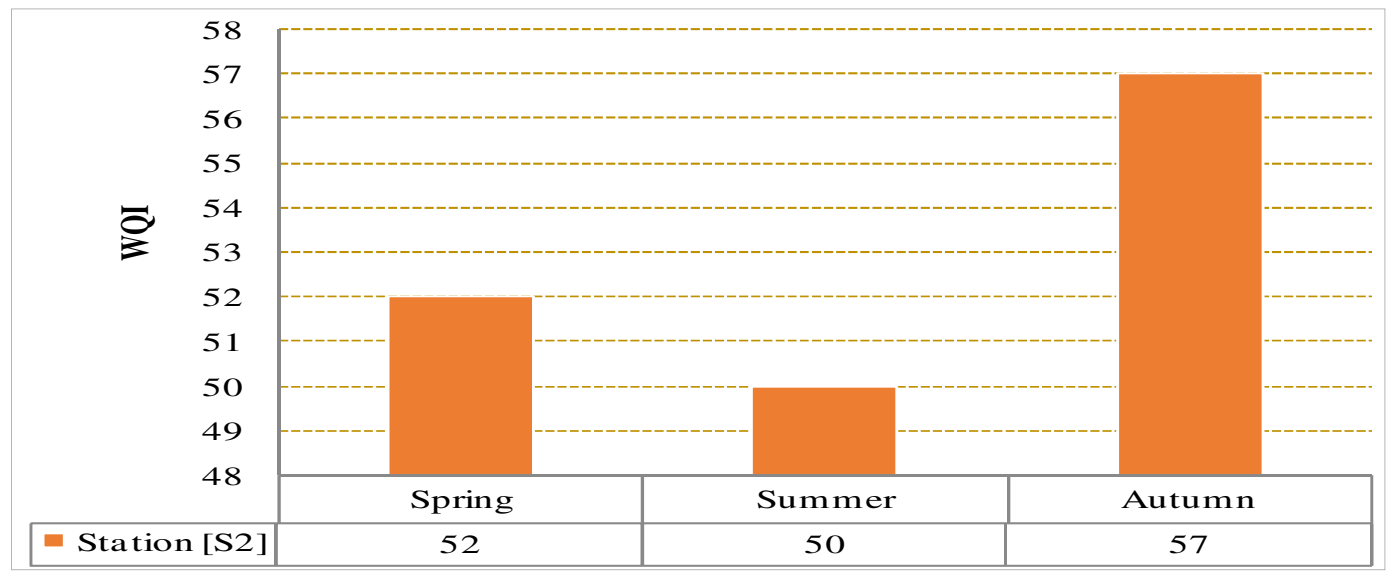

Fig.- 3: WQI in the sampling station S2

\section{WQI at Station $\left[S_{3}\right]$}

Water Quality Index (WQI) at (S3) station during the three seasons: spring, summer and autumn indicated values as in Fig.-4. At this station, WQI's highest value was obtained during the autumn season (WQI 69), whereas the lowest value was obtained during summer (WQI 67). In general, in all three seasons, the water according to WQI was of medium quality, thus belonging to class "C" in terms of quality. Class "C" means Medium, WQI: 50-70 (Drinking water source after conventional treatment and disinfection). 
RASĀYAN J. Chem.

Vol. 11 | No. 2 |653-660 | April - June | 2018

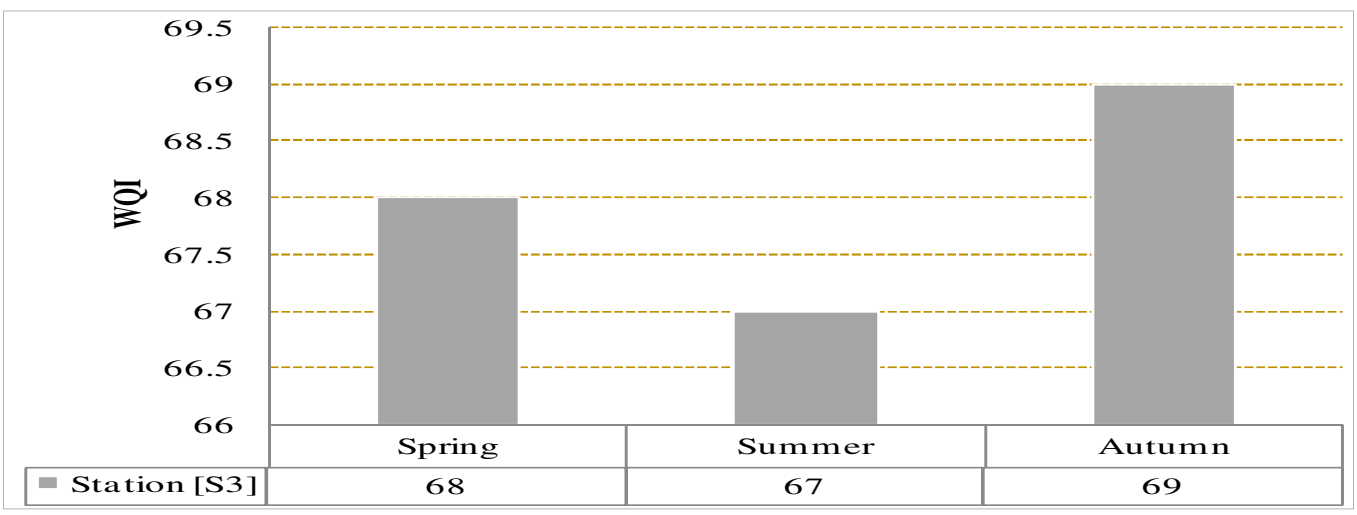

Fig.- 4: WQI in the sampling station S3

\section{WQI at Station $\left[S_{4}\right]$}

Water Quality Index (WQI) at (S4) station during the three seasons: spring, summer and autumn indicated values as in Fig.-5. At this station, WQI's highest value was obtained during the summer (WQI 46), whereas the lowest value was obtained during autumn (WQI 40). In general, at this station, in all three seasons, according to WQI the water was of poor quality, thus belonging to class "E" in terms of quality. Class "E" means Bad, WQI: 25-50 (Propagation of Wild life and Fisheries).

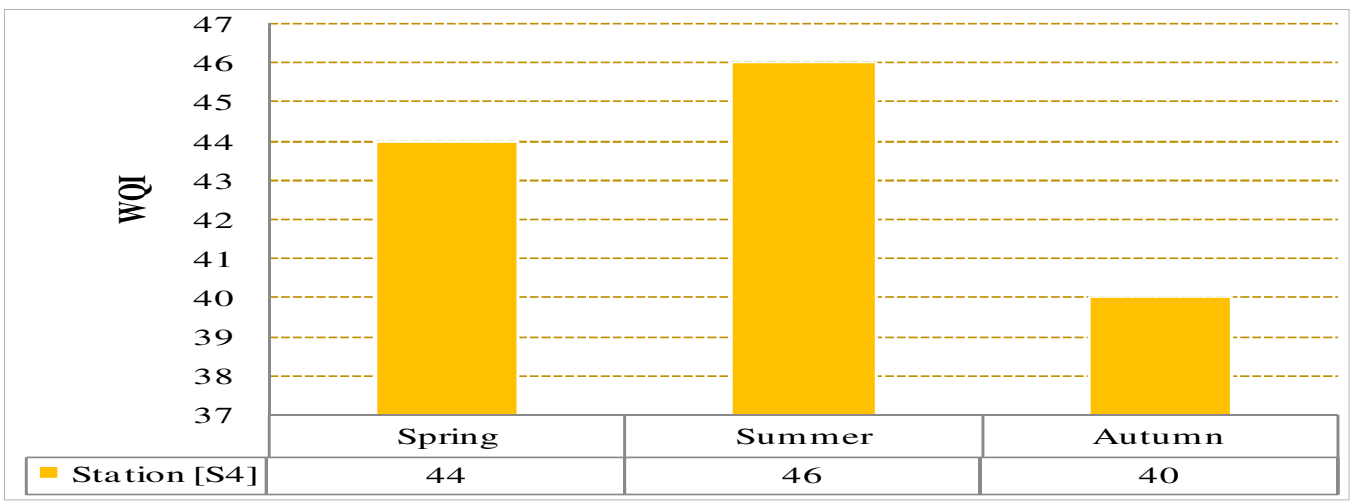

Fig.- 5: WQI in the sampling station S4

\section{WQI at Station $\left[\mathbf{S}_{5}\right]$}

Water Quality Index (WQI) at the station (S5) during the three seasons: spring, summer and autumn indicated values as in Fig.-6. At this station, the highest value of WQI was obtained during spring (WQI 54), which indicates that water quality index belongs to class " $C$ ". Class " $C$ " means Medium, WQI: 50-70 (Drinking water source after conventional treatment and disinfection), while during the other two seasons (summer and autumn) WQI indicates that water quality is bad. Class "E" means Bad, WQI: 25-50 (Propagation of Wild Life and Fisheries).

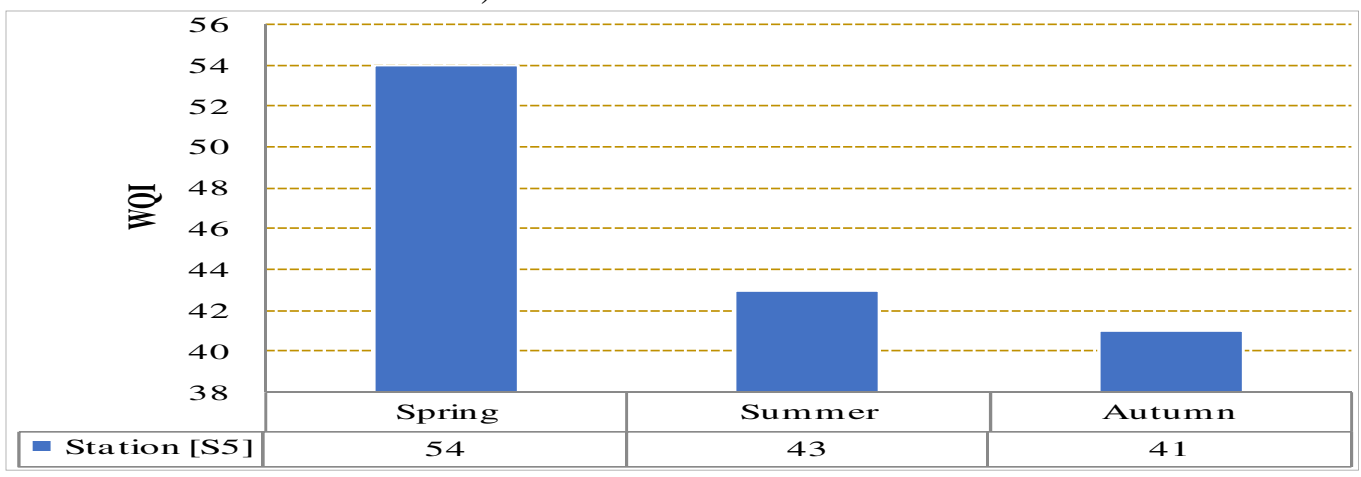

Fig.- 6: WQI in the sampling station S5

657 


\section{WQI at Station $\left[\mathrm{S}_{6}\right]$}

Water Quality Index (WQI) at (S6) station during the three seasons: spring, summer and autumn indicated values as in Fig.-7. At this station, WQI's highest value was obtained during spring (WQI 48), whereas the lowest value was obtained during autumn (WQI 38). In general, at this station, in all three seasons, according to WQI, the water was of bad quality, thus belonging to class "E" in terms of quality. Class "E" means Bad, WQI: 25-50 (Propagation of Wildlife and Fisheries).

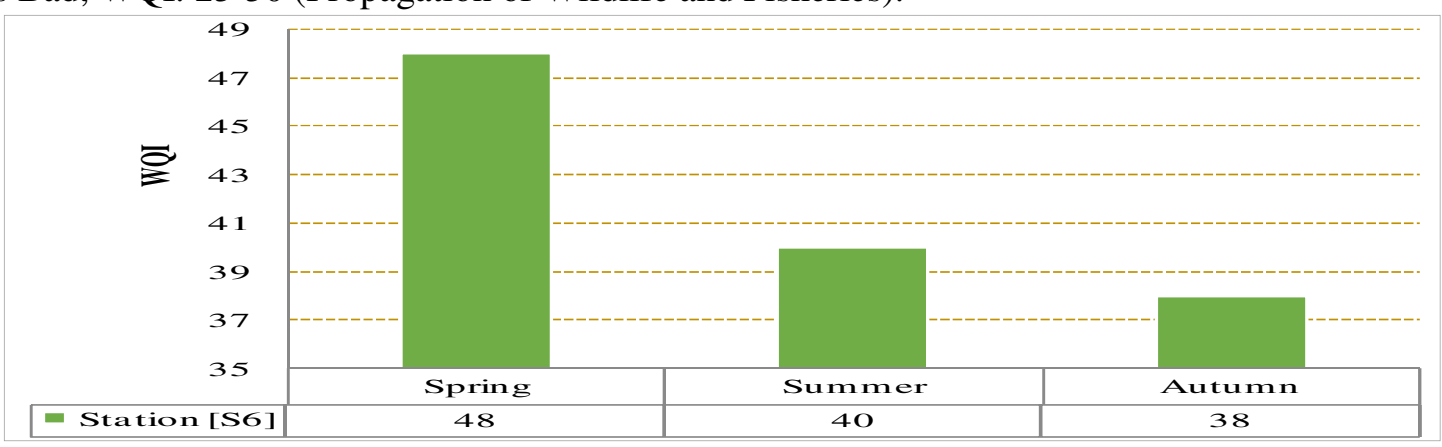

Fig.- 7: WQI in the sampling station S6

\section{WQI at Station $\left[\mathrm{S}_{7}\right]$}

Water Quality Index (WQI) at (S7) station during the three seasons: spring, summer and autumn indicated values as in Fig.-8. At this station, WQI's highest value was obtained during summer (WQI 48), whereas the lowest value was obtained during autumn (WQI 38). In general, at this station, in all three seasons, according to WQI the water was of bad quality, thus belonging to class "E" in terms of quality. Class " $E$ " means Bad, WQI: 25-50 (Propagation of Wildlife and Fisheries).

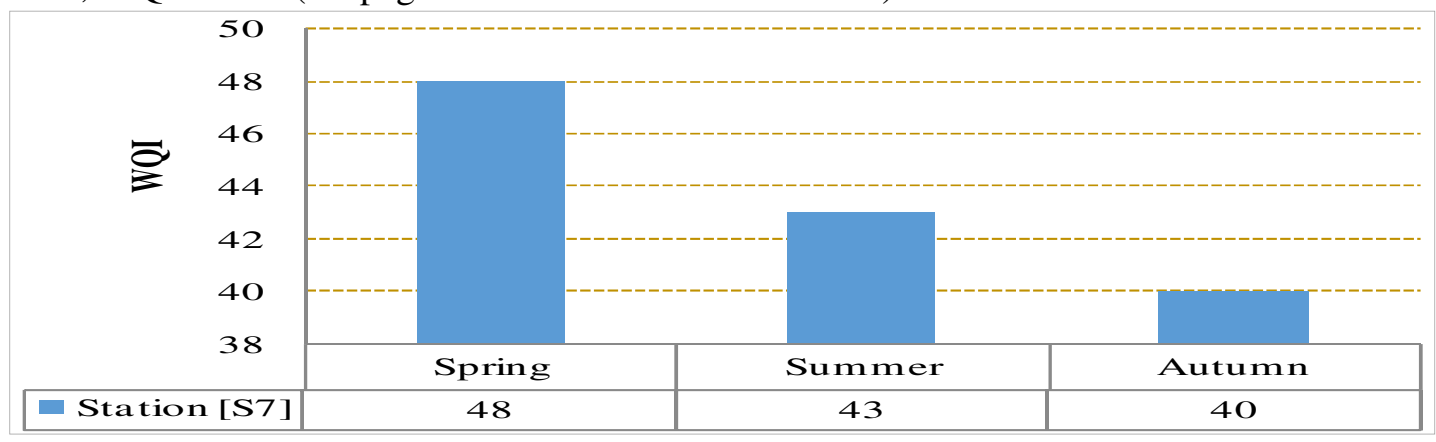

Fig.- 8: WQI in the sampling station S7

\section{WQI at Station $\left[S_{8}\right]$}

Water Quality Index (WQI) at (S8) station during the three seasons: spring, summer and autumn indicated values as in Fig.-9. At this station, WQI's highest value was obtained during spring and summer (WQI 43), whereas the lowest value was obtained during autumn (WQI 36). In general, at this station, in all three seasons, according to WQI the water was of bad quality, thus belonging to class "E" in terms of quality. Class "E" means Bad, WQI: 25-50 (Propagation of Wildlife and Fisheries).

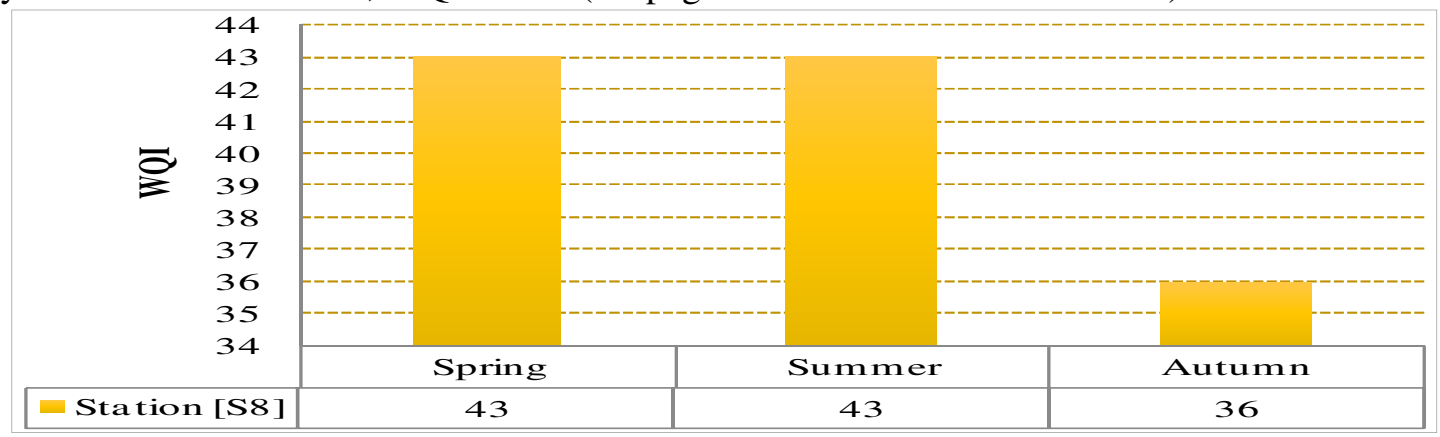

Fig.- 9: WQI in the sampling station S8

$$
658
$$




\section{Overall WQI Values in Different Seasons}

Variation in Water Quality Index (WQI) of surface water at eight measuring stations for the three seasons: spring, summer and autumn is shown in Fig.-10.

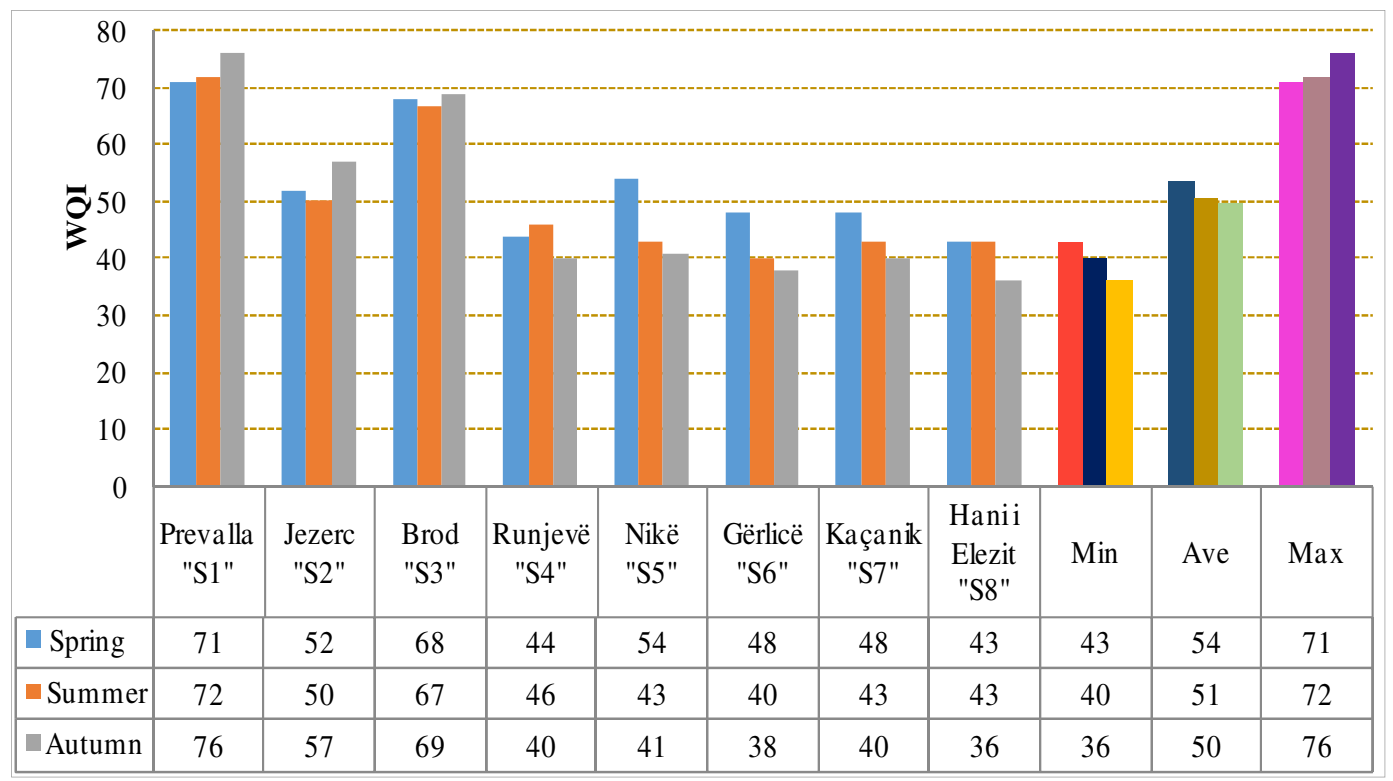

Fig.- 10: All WQI values in different seasons

\section{Spring Season}

During this time the values for the quality of water extracted by WQI method vary from WQI 43 at Hani i Elezit (S8) station, which is located at the bottom of the basin (Lepenc river), thus belonging to "E" class (Propagation of Wild Life and Fisheries), the highest value of WQI 71 was obtained at Prevalla (S1) station, which is located in the upper part of the basin (Lepenc River) and, based on the WQI, the water is of good quality, thus belonging to "B" class (Outdoor bathing, Recreation, Propagation \& Maintenance of a Healthy, Well-Balanced Population of Fish\&Wildlife), whereas at all other stations the quality of water according to WQI was bad and belonged to "E" class (Propagation of Wild Life and Fisheries). Based on the average value of $\mathrm{WQI}_{\mathrm{avg}}=54$ the water quality during this season is medium, and belongs to Class " $\mathrm{C}$ ". Class "C" means Medium, WQI: 50-70 (Drinking water source after conventional treatment and disinfection)

\section{Summer Season}

During this season the highest values of WQI=72 and WQI 67 were obtained at Prevalla (S1) and Brod (S3) stations which shows that the water at these stations according to WQI is of good quality and belongs to class "B". The lowest value of WQI=40 was obtained at Gërlicë (S6) station and according to WQI, the water is of bad quality, thus belonging to class "E". Similarly, other stations according to WQI have shown that water is of bad quality and belongs to class " $\mathrm{E}$ ". The average value of WQI $\mathrm{I}_{\text {avg, }}$ which is 51 , indicates that water is of medium quality (slightly tends towards medium), and belongs to class " $\mathrm{C}$ ".

\section{Autumn Season}

During this season the highest values of WQI=76 and WQI 69 were obtained at Prevalla (S1) and Brod (S3) stations, indicating that water at these stations according to WQI is of good quality and belongs to class "B". The lowest value of WQI=36 was obtained at Hani i Elezit (S8) station and, according to WQI, the water is of bad quality, thus belonging to class "E". Similarly, other stations, according to WQI, have shown that water is of bad quality and belongs to class "E". The average value of $\mathrm{WQI}_{\mathrm{avg}}$, which is 50 , indicates that water is of medium/bad quality, and belongs to class " $C$ "/" $\mathrm{E}$ ". 


\section{CONCLUSION}

Based on the results obtained from eight measuring stations during the three seasons of the year, the surface water quality at Lepenc River basin according to Water Quality Index (WQI) varies between 36 to 76. The highest values of WQI during the three seasons were obtained at Prevalla (S1) measuring station, and at all times the water was of good quality with a slight tendency to increase the quality from spring to autumn. The results show that WQI during the spring season indicates a better durability in terms of water quality of this basin.

According to WQI, surface water in this basin was of medium and bad quality. Medium quality was recorded in the upper part of the basin, while in the middle and lower part of the basin there was a decline of water quality. Such a decline of water quality comes as a result of the inhabited, agricultural, and industrial areas as well as another human (anthropogenic) activities.

It is recommended to establish a permanent monitoring system for surface waters in this basin; to undertake measures to treat polluted urban and industrial waters before discharging them into river flows; to reduce the use of chemical fertilizers and pesticides in agricultural land, as well as anthropogenic activities related to the use of inert ingredients and rock masses in areas close to river flows.

\section{REFERENCES}

1. The State of Water Report in Kosovo (MESP) Pristina, pp.1-120 (2010).

2. Municipality of Development Plan, City Kaçanik, pp.1,80 (2011).

3. B. Patel, Development of Water Quality Index: A case of Sabarmati River front development project. In proceedings of International Journal of Academic Conference, p. 13(1), (2011).

4. B. Oram, Monitoring the quality of Surface waters. B.F. Environmental Consultants (2018). Inc.,http://www.water-research.net/watrqualindex/

5. ISO. 5667-6:Water quality- Sampling-Part 6:(2014).

6. Robert A. Pollack, Lorraine Findlay, Walter Mondschein, R. Ronald Modesto 2009, Laboratory Exercises in Microbiology, USA, pp 25-46.

7. Emanuel Goldman, Lorrence H. Green, 2008, Practical Hanbook of Microbiology, USA, pp 11-30.

8. M. Plakolli, 2001, Practicum for Microbiology. Pristina . pp 15-150.

9. N.C. Kankal, M.M. Indurkar, S.K. Gudadhe and S.R. Wate, S.l. India, 26(1), 39 (2012).

10. H. Boyacioglu, Water S.A, 33(1) (2007), DOI:10.4314/wsa.v33i1.47882

11. Mitra. S, Ghosh. S, Kanta Satpathy.K, Deb Bhattacharya. B, Kumar Sarkar. S, Mishra. P, P. Raja, Marine Pollution Bulletin,126,592(2018), DOI: 10.1016/j.marpolbul.2017.09.053

12. M.V. Amé, S.F. Pesce(2015) Spatial and Temporal Changes in Water Quality Along the Basin. In: Wunderlin D.A. (eds) The Suquía River Basin (Córdoba, Argentina). The Handbook of Environmental Chemistry, 62, Springer, Cham., DOI: https://doi.org/10.1007/698_2015_4

[RJC-3015/2018] 